Received: 2019.01.30 Accepted: 2019.04.10 Published: 2019.11 .26

\title{
Inhibition of Nasopharyngeal Carcinoma by Beta-Lapachone Occurs by Targeting the Mammalian Target of Rapamycin (mTOR)/PI3K/ AKT Pathway, Reactive Oxygen Species (ROS) Production, and Autophagy Induction
}

Authors' Contribution: Study Design A Data Collection B Statistical Analysis C Data Interpretation D Manuscript Preparation E Literature Search F Funds Collection G

Corresponding Author: Source of support:
$B C D 1$ Yongqing Han

CDEF 2 Dayou Shi

AEFG 3 Jingao Li
1 Department of Oncology, Nanchang University, Nanchang, Jiangxi, P.R. China 2 Department of Oncology, Jiujiang First People's Hospital, Jiujiang, Jiangxi, P.R. China

3 Department of Radiotherapy, Jiangxi Tumor Hospital, Nanchang, Jiangxi, P.R. China

Background: Beta-lapachone has been shown to exhibit potent anti-cancer effects against various cell lines. In the present study, we examined the anti-cancer effects of beta-lapachone, a quinone, against human HNE1 nasopharyngeal carcinoma cells, and also assessed its effects on cellular migration and invasion, autophagy, mTOR/PI3K/AKT signalling pathway, and ROS production.

Material/Methods: $\quad$ CCK-8 cell counting assay was used to assess cell viability effects after lapachone treatment. Its effects on the mTOR/PI3K/AKT biochemical pathway were examined by Western blot analysis. Transmission electron microscopy was used to study autophagy induced by beta-lapachone. Effects on cell invasion and cell migration were evaluated by Transwell method.

Results: The results revealed that beta-lapachone suppresses the proliferation of HNE1 cells, with an $\mathrm{IC}_{50}$ of $30 \mu \mathrm{M}$. These growth-inhibitory effects of beta-lapachone were found to be dose-dependent. The investigation of the effects of beta-lapachone on the mTOR/PI3KAKT signalling pathway showed that beta-lapachone blocked this pathway in a concentration-dependent manner. Beta-lapachone also inhibited the migration and invasion of HNE1 nasopharyngeal cancer cells, as shown by Transwell assay. The fluorescence microscopy analysis showed that beta-lapachone increased production of reactive oxygen species (ROS), which is also linked with a concentration-dependent decrease in mitochondrial membrane potential (MMP) levels. Electron microscopy analysis showed that beta-lapachone caused the development of the autophagosomes, and the frequency of the autophagosomes increased with increased dosage of beta-lapachone. The beta-lapachone-triggered autophagy was also associated with increased protein levels of LC3 II and decreased levels of p62.

Conclusions: The findings of this study suggest that beta-lapachone inhibits the growth of nasopharyngeal cancer cells by promoting autophagy, and it may be useful in cancer drug discovery paradigms.

MeSH Keywords: $\quad$ Autophagy • Cell Migration Assays • Nasopharyngeal Neoplasms • Neoplasm Invasiveness

Full-text PDF: https://www.medscimonit.com/abstract/index/idArt/915463

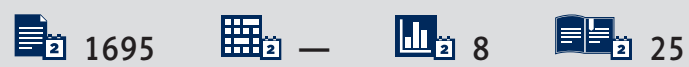




\section{Background}

Quinones are secondary metabolites of plant origin, classified as anthroquinone, phenanthrenequinone, and naphthoquinone, depending on the number of benzene rings in its basic chemical scaffold [1]. These metabolites are extensively spread across the plant kingdom. Polygonaceae, Leguminosae, Labiatae, and Boraginaceae are some of the families that are rich sources of quinones [1,2]. Quinones have been shown to exhibit strong bioactivities such as anti-microbial, antibacterial, and anti-cancer effects [2-4]. Several of the plant-derived quinones have cancer cell growth-inhibitory effects, and thymoquinone has been documented to trigger programmed cell death of cancer cells [5]. The $\gamma$-tocopheryl quinone has been documented to suppress growth of tumor cells through activation of numerous caspases [6]. Beta-lapachone is an important naphthoquinone isolated from various plant species [7]; it has been shown to suppress cancer cell growth and to halt uncontrolled growth of pancreatic cancer cells mediated through induction of programmed cell death [8]. In colon cancer cells, beta-lapachone also induces cell cycle arrest [9]. However, the anti-cancer effects of beta-lapachone have not been examined in human nasopharyngeal tumor cells. The present study was therefore designed to demonstrate the antitumor effect of beta-lapachone in HNE1 human nasopharyngeal cancer cells. Nasopharyngeal cancer is a common form of neck and head cancer [10]. The treatment of nasopharyngeal carcinoma is limited by early metastasis and the adverse effects of available chemotherapeutic agents [11]. Moreover, development of multi-drug resistance in nasopharyngeal cancer patients makes it challenging to treat $[12,13]$. In the present study, we developed various assays exhibiting the anticancerous effects of $\beta$-lapachone in nasopharyngeal carcinoma cells, and we also explored the various mechanisms of action.

\section{Material and Methods}

\section{Reagents and cell culture conditions}

DMEM and RPMI-1640 media (obtained from HyClone; GE Healthcare, USA) were used to maintain the HNE1 cancer cells and the normal (NP460) cells. These cells were procured from the Cancer Research Institute of Beijing (Beijing, China). The medium was supplemented with $10 \%$ fetal bovine serum, streptomycin $(100 \mu \mathrm{g} / \mathrm{ml})$, and penicillin $\mathrm{G}(100 \mathrm{U} / \mathrm{ml})$ (Himedia, Pennsylvania, USA) in an incubator at $37^{\circ} \mathrm{C}$ with $5 \% \mathrm{CO}_{2}$. Cell culture plasticware was procured from BD Biosciences (San Jose, CA, USA).

\section{Cell viability determination}

The viability of nasopharyngeal carcinoma cells was assessed via CCK- 8 assay. In brief, the transfected HNE1 cells were subjected to treatment with various concentrations of beta-lapachone ( 0 to $320 \mu \mathrm{M}$ ) at $37^{\circ} \mathrm{C}$ for $24 \mathrm{~h}$ after seeding in 96 -well plates. Thereafter, freshly prepared CCK-8 solution $(10 \mu \mathrm{L})$ was added to the HNE1 and NP460 cell cultures and then incubated for $2 \mathrm{~h}$ at $37^{\circ} \mathrm{C}$ in a humidified incubator. Optical density (OD450) was measured by using a microplate reader, after which cell growth inhibition was calculated from optical density.

\section{Transmission electron microscopy}

After beta-lapachone treatment at varied doses $(0,15,30$, and $60 \mu \mathrm{M})$, the HNE1 nasopharyngeal cancer cells were fixed with $4 \%$ glutaraldehyde solution and then post-fixed with $1.5 \%$ osmium tetraoxide solution and $0.05 \mu \mathrm{M}$ sodium cacodylate and then dehydrated using alcohol. After dehydration, cells were loaded in Epon 812 and further investigations were carried out using a Zeiss CEM 902 electron microscope.

\section{ROS and MMP estimation}

To calculate the ROS levels induced by beta-lapachone, the HNE1 cells were initially cultured for $24 \mathrm{~h}$ at $37^{\circ} \mathrm{C}$. The cells were then treated with increasing doses of beta-lapachone $(0,15,30$, and $60 \mu \mathrm{M})$ for $24 \mathrm{~h}$. Following drug treatment, the medium from the cell cultures was discarded and the cells were stained with a fluorescent dye - (H2DCF-DA) (5 $\mu \mathrm{M})$ 2',7'-dichlorodihydrofluorescein diacetate - to determine the ROS level. For measuring MMP, rhodamine 123 dye was used in fluorescence microscopy.

\section{Transwell assay}

To analyse the effect of beta-lapachone $(0,15,30$, and $60 \mu \mathrm{M})$ on the invasion ability of HNE1 cells, we used the Transwell method (8-mm pore size, procured from Corning, NY, USA). We placed $200 \mathrm{ml}$ of SW480 cell culture into the upper chambers, and the lower chambers were filled with medium only. Afterwards, the cell cultures were incubated and removed from the upper chambers and invaded cells were collected. Fixation of invaded cells was done by methanol and then crystal violet dye was used for staining. Finally, using inverted microscopy at $200 \times$ magnification, the invaded cells were counted. The migration ability of cells was also assessed with the same procedure but without Matrigel coating of the Transwell chambers.

\section{Western blot analysis}

Determination of the expressions various proteins was carried out by Western blot analysis. The beta-lapachone-treated $(0,15,30$, and $60 \mu M)$ HNE1 cells were harvested by centrifugation. The HNE1 cells were then subjected to lysis using a protease inhibitor lysis buffer. We ran $45-\mu$ g protein extracts on SDS-PAGE followed by transfer to a PVDF (polyvinylidene 


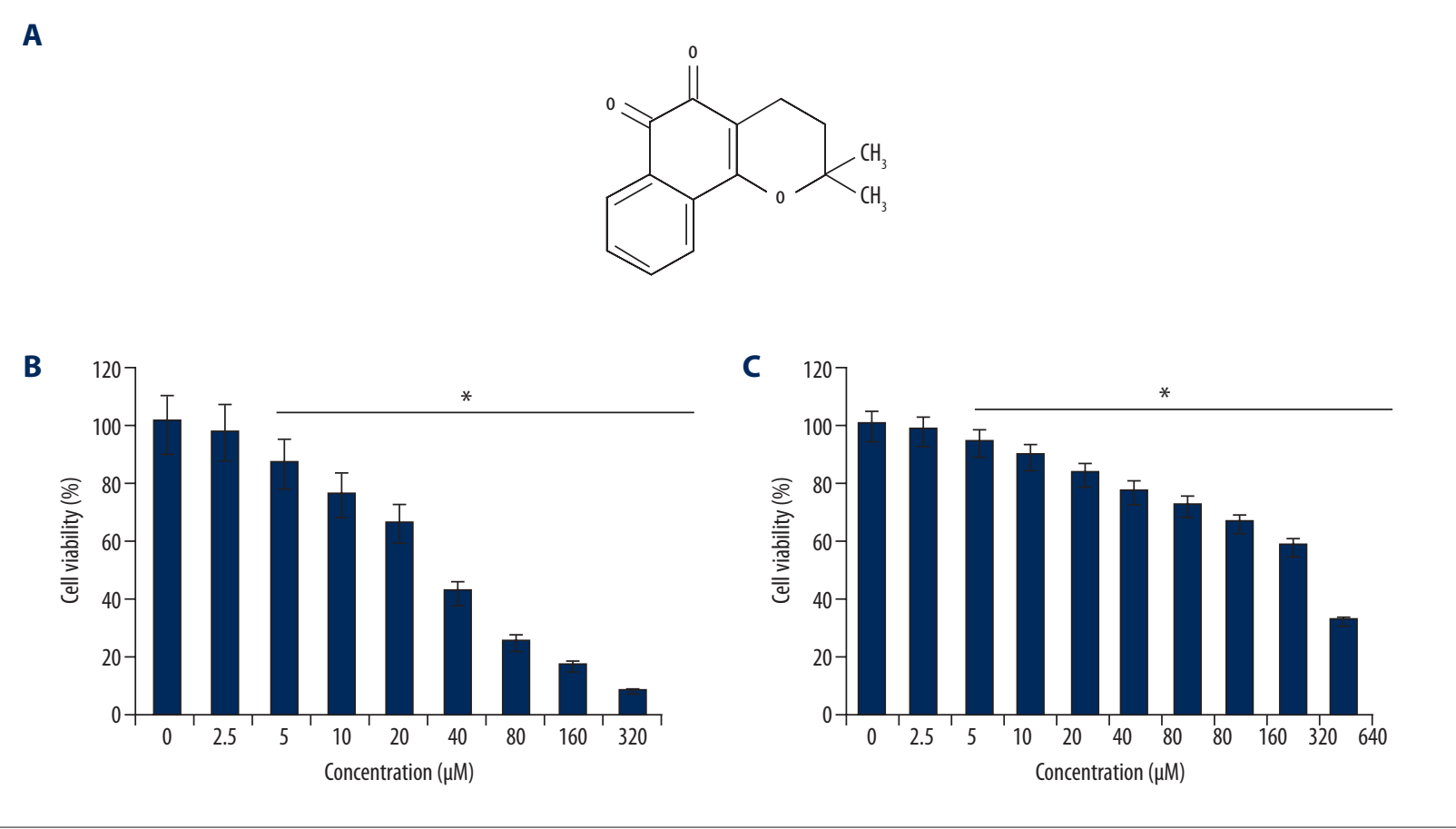

Figure 1. (A) Chemical structure of beta-lapachone. (B, C) CCK-8 analysis indicating impact of beta-lapachone on viability of HNE1 cancer cells. The experiments were done in triplicate and the findings are presented as mean $\pm S D\left({ }^{*} P<0.05\right)$.

fluoride) membrane. Afterwards, membranes were blocked using non-fat milk and incubated for $1 \mathrm{~h}$ at room temperature. Then, blocked membranes were exposed to primary antibody treatment followed by incubation overnight at $4^{\circ} \mathrm{C}$. Next, membranes were washed and incubated for $1 \mathrm{~h}$ with horseradish peroxidase-conjugated goat anti-mouse antibody. Western blot band signals were detected using the Odyssey Infrared Imaging System (LI-COR, USA). As a control for normalisation, we used beta-actin.

\section{Statistical analysis}

All experiments were performed 3 times. Data are represented as mean $\pm \mathrm{SD}$, and the $t$ test was used with GraphPad Prism 7 software for statistical evaluation. A statistically significant difference was defined as $p<0.05$.

\section{Results}

\section{Beta-lapachone inhibited proliferation of HNE1 nasopharyngeal cancer cells}

To ascertain the anti-cancer effects of beta-lapachone (Figure 1A), the HNE1 cells were treated with $0-320-\mu M$ concentrations of beta-lapachone and then subjected to CCK8 assay. The outcomes of the CCK8 cell viability assay showed that betalapachone caused concentration-dependent decreases $(p<0.05)$ in the viability of HNE1 cells (Figure 1B). We found that at $24 \mathrm{~h}$ of incubation, beta-lapachone exhibits an $\mathrm{IC}_{50}$ of $30 \mu \mathrm{M}$ against the HNE1 nasopharyngeal carcinoma cells. The anticancer effects were also examined against the normal NP460 cells, showing that beta-lapachone exerted minimal toxic effects, as shown by the $I_{50}$ of $100 \mu \mathrm{M}$ in the normal NP460 cells (Figure 1C).

\section{Beta-lapachone blocked the mTOR/PI3K/AKT biochemical signalling cascade}

The mTOR/PI3K/AKT biochemical signalling pathway is a therapeutic target for the treatment of various cancers. We assessed the effects of beta-lapachone at concentrations of $0,15,30$, and $60 \mu \mathrm{M}$ on the phosphorylation status of mTOR, PI3K, and AKT (Figure 2). The findings of Western blot assay showed that the beta-lapachone molecule significantly $(p<0.05)$ suppressed the phosphorylation of AKT, mTOR, and PI3K in a dose-dependent manner. However, the total protein levels of AKT, mTOR, and $\mathrm{PI} 3 \mathrm{~K}$ remained apparently unaltered.

\section{Beta-lapachone inhibited the migration of the HNE1 cells}

Transwell assay was used to determine the impact of betalapachone on the migration ability of HNE1 cells at concentrations of $0,15,30$, and $60 \mu \mathrm{M}$, showing that beta-lapachone repressed the migration of HNE1 cells in a concentration-dependent manner (Figure 3). 


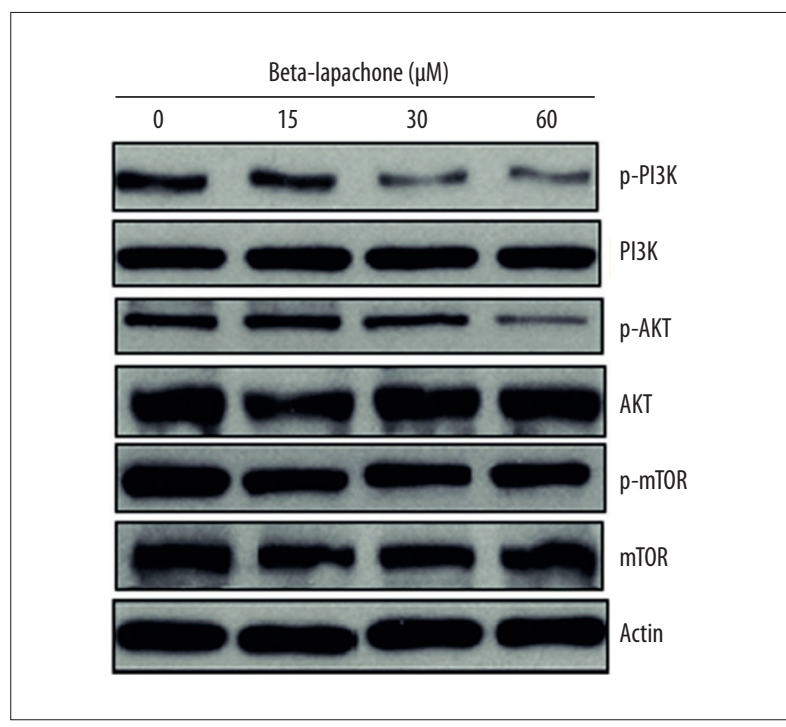

Figure 2. Effects of beta-lapachone on the mTOR/PI3K/AKT pathway in HNE1 cancer cells as determined by Western blot analysis. The experiments were performed in triplicate.

\section{Beta-lapachone inhibited the invasion ability of HNE1 cells}

We also performed Transwell analysis to assess the effect of beta-lapachone on the invasive ability of HNE1 cells at 0,15 ,
30 , and $60 \mu \mathrm{M}$ concentrations. The results divulged that betalapachone repressed the invasive ability of HNE1 tumor cells (Figure 4). These effects of beta-lapachone were found to be concentration-dependent.

\section{Effects of beta-lapachone on ROS and MMP levels of HNE1 cells}

The effects of beta-lapachone were examined at ROS and MMP levels in HNE1 cells at concentrations of $0,15,30$, and $60 \mu \mathrm{M}$ by fluorescence microscopy. We found that beta-lapachone treatment led to a strong upsurge in the ROS levels of the HNE1 tumor cell lines (Figure 5), along with decreased MMP levels (Figure 6). These effects of beta-lapachone on the ROS and MMP levels were dose-dependent.

\section{Beta-lapachone led to autophagic induction in the HNE1 cells}

TEM examination of the beta-lapachone-treated HNE1 cells indicated that beta-lapachone causes development of autophagosomes in HNE1 cells, which is a hallmark of autophagy (Figure 7). Beta-lapachone also increased the protein levels of LC3-II and decreased p62 expression, which indicates autophagy. However, no apparent effect was seen on LC3-I protein expression (Figure 8).

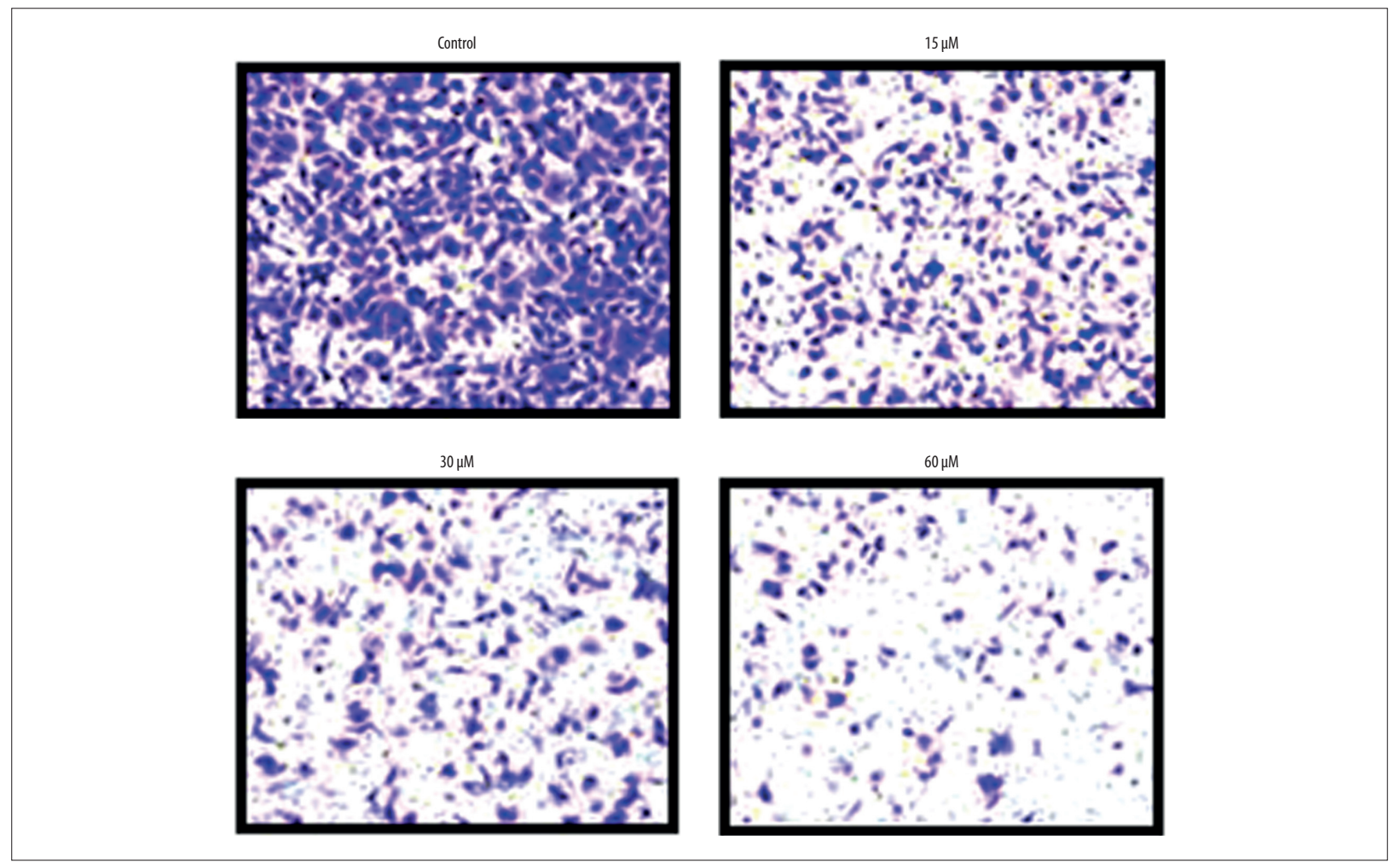

Figure 3. Effects of beta-lapachone on migration of HNE1 nasopharyngeal carcinoma cells as determined by Transwell analysis. Each experiment was performed in triplicate. 


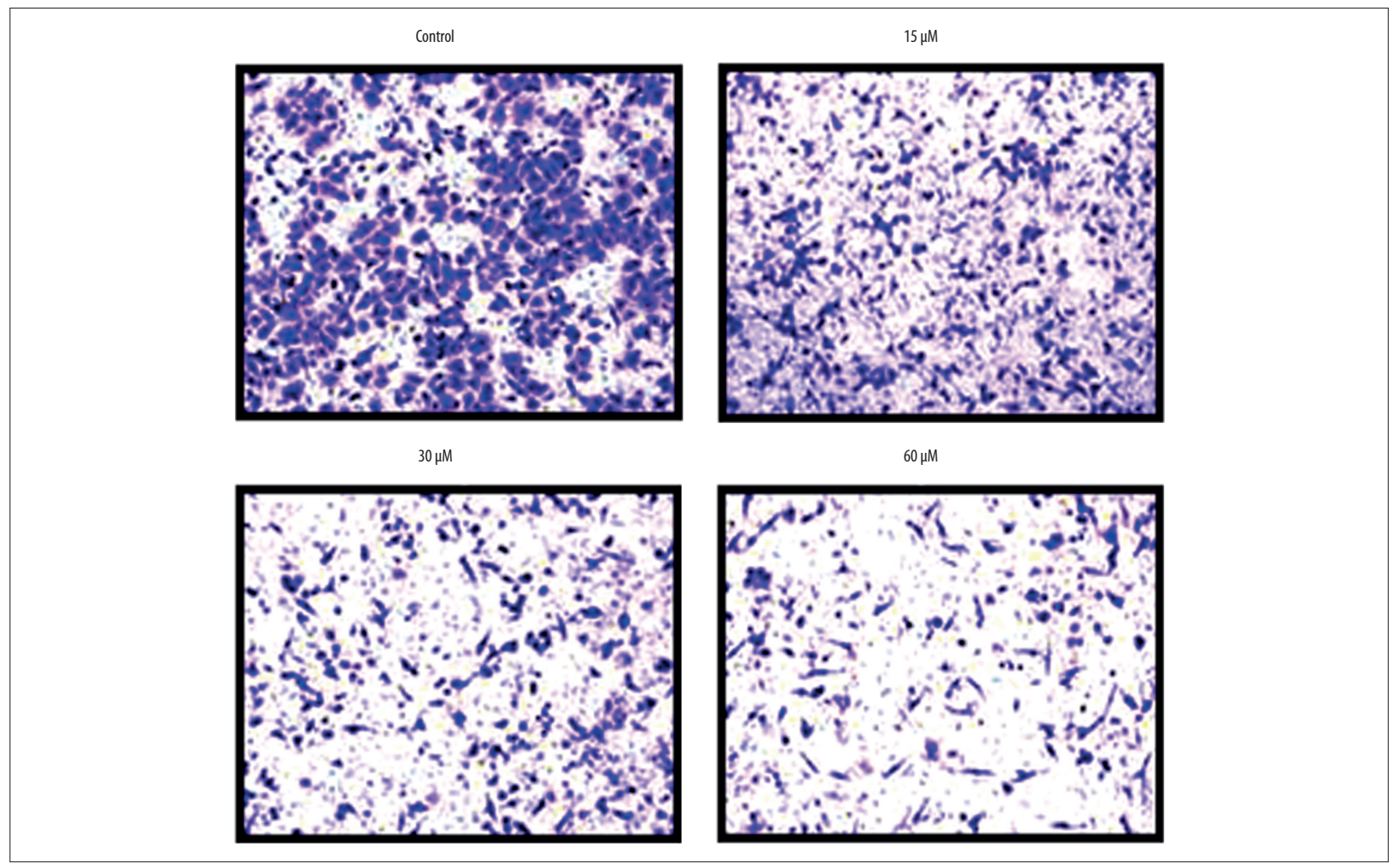

Figure 4. Effects of beta-lapachone on the invasion of the HNE1 nasopharyngeal carcinoma cells as determined by Transwell assay. The experiments were performed in triplicate.

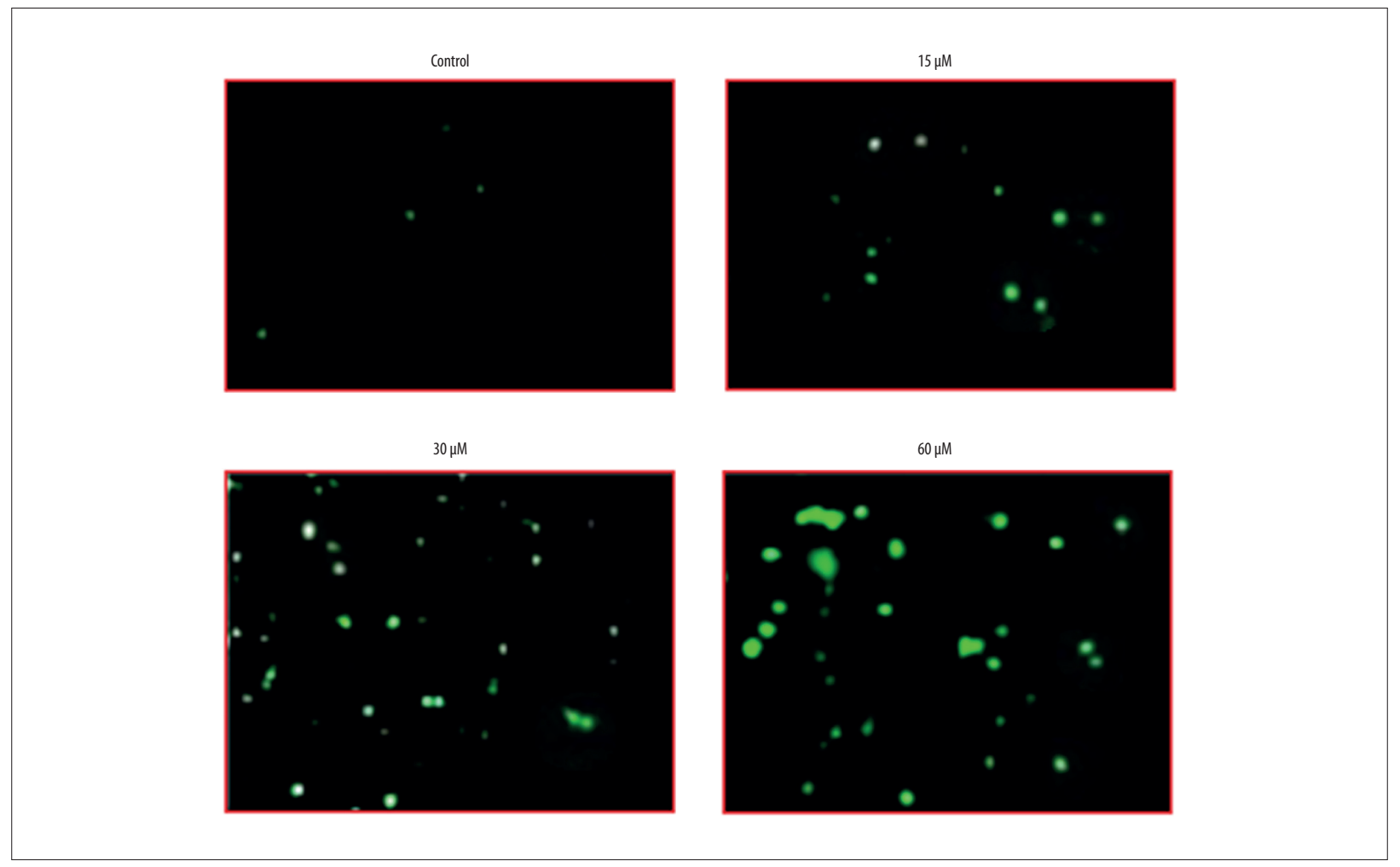

Figure 5. Effects of beta-lapachone on ROS levels in HNE1 nasopharyngeal carcinoma cells as determined by fluorescence microscopy. The experiments were performed in triplicate. 


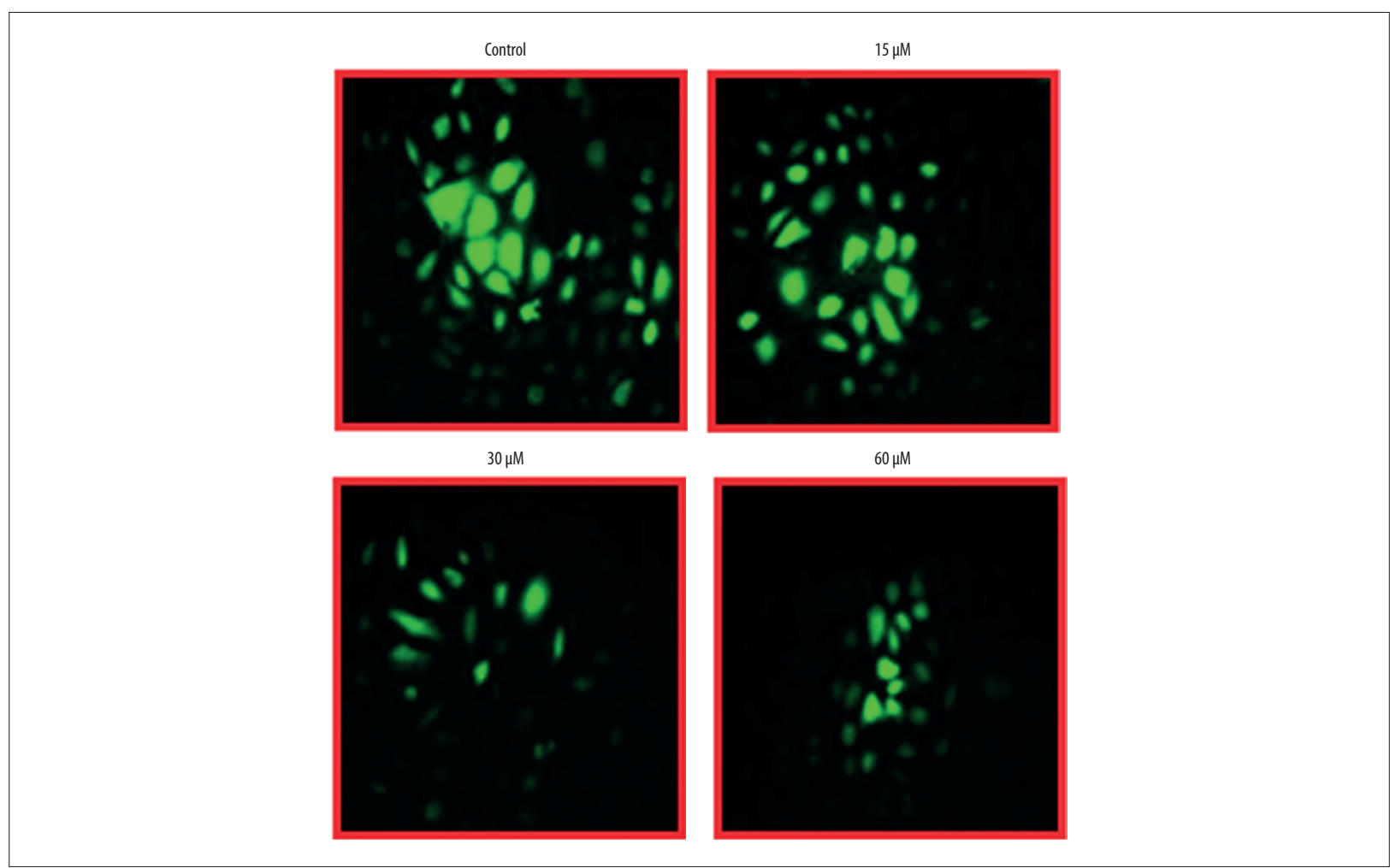

Figure 6. Effects of beta-lapachone on MMP levels in HNE1 nasopharyngeal carcinoma cells as determined by fluorescence microscopy. The experiments were performed in triplicate.

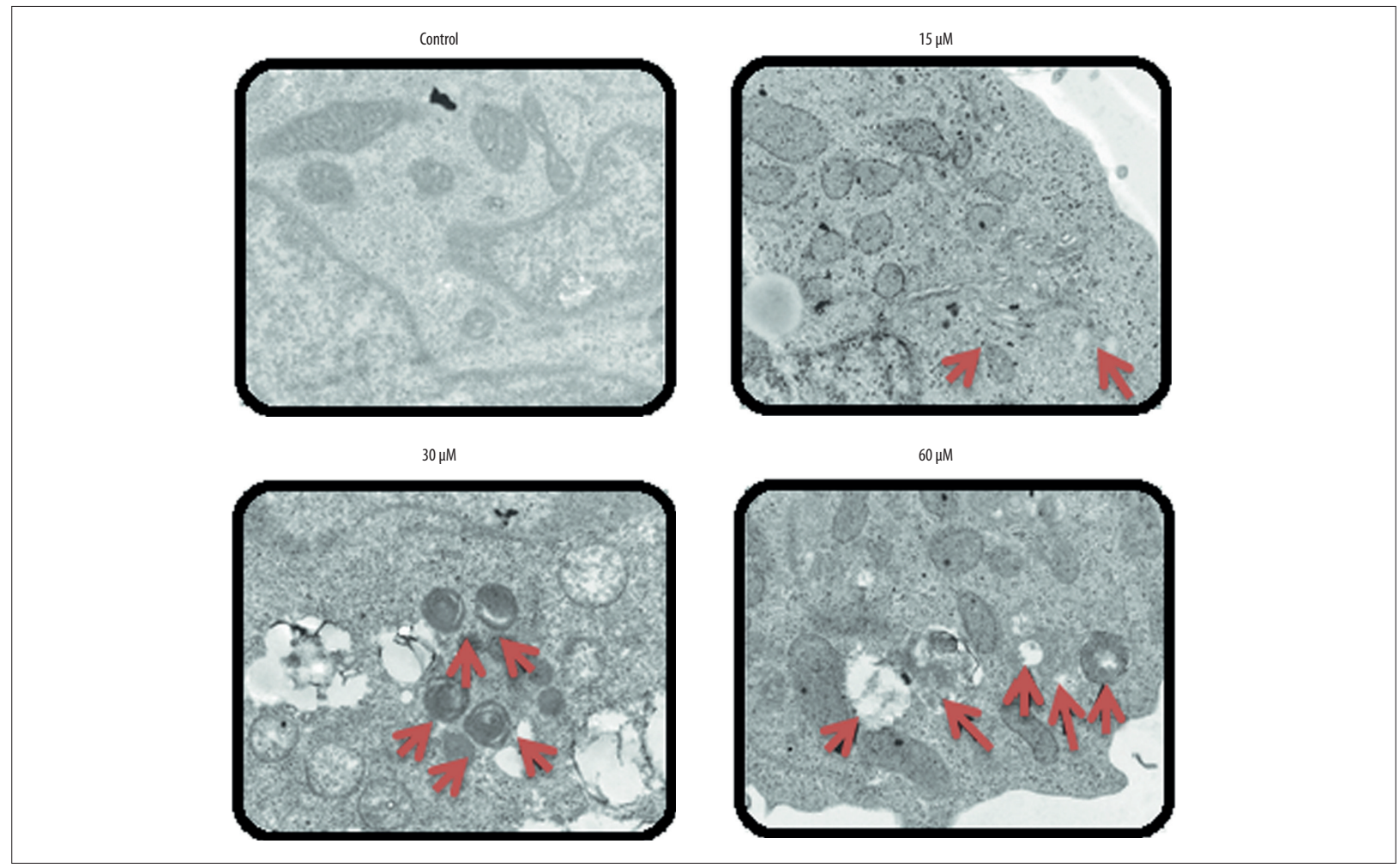

Figure 7. Beta-lapachone triggers autophagy in HNE1 nasopharyngeal carcinoma cells (arrows indicate autophagosomes). The experiments were performed in triplicate. 


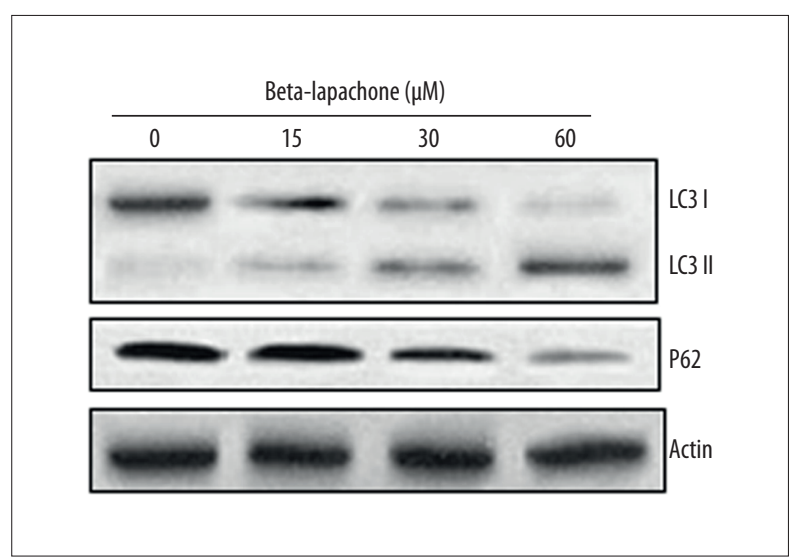

Figure 8. Effect of beta-lapachone on autophagy-related proteins in HNE1 cells as determined by Western blot analysis. The experiments were performed in triplicate.

\section{Discussion}

Nasopharyngeal carcinoma is a common malignant tumor in Southeast Asia and Southern China. Metastasis of nasopharyngeal carcinoma at an early stage is associated with short survival times [14]. The 5-year survival rate with combined treatment with cisplatin radiotherapy and chemotherapy is around 50-60\% [15,16]. Surgical removal, systemic chemotherapy, or radiotherapy are used for treatment of nasopharyngeal carcinoma. Nonetheless, because of the adverse impact of these treatment strategies, patient quality of life is drastically compromised [17]. Beta-lapachone is a potent anti-cancer molecule and has been shown to halt the growth of several types of cancers [18-20]. Here, we assessed the anti-cancer effects of beta-lapachone against human nasopharyngeal HNE1 cancer cells. Our results confirm the conclusions of previous studies showing that beta-lapachone exerts anti-cancer effects on tumor cells; for instance, beta-lapachone has been revealed to stop the growth of lung cancer cells [21]. Similarly, another

\section{References:}

1. Wang ZT et al: Shanghai Scientific and Technical Publishers. 2009.

2. Wang JK, Li A, Wang H, Xu XY: Comparative studies on purgative potency among three species of certified rhubarb. Zhongguo Zhong Yao Za Zhi, 2006; 31(23): 1987-91 [in Chinese]

3. Padhye $S$, Dandawate $P$, Yusufi $M$ et al: Perspectives on medicinal properties of plumbagin and its analogs. Med Res Rev, 2012; 32(6): 1131-58

4. Aithal BK, Kumar MR, Rao BN et al: Juglone, a naphthoquinone from walnut, exerts cytotoxic and genotoxic effects against cultured melanoma tumor cells. Cell Biol Int, 2009; 33(10): 1039-49

5. Shoieb AM, Elgayyar M, Dudrick PS et al: In vitro inhibition of growth and induction of apoptosis in cancer cell lines by thymoquinone. Int J Oncol, 2003; 22(1): 107-13

6. Calviello G, Di Nicuolo F, Piccioni E et al: $\gamma$-Tocopherylquinone induces apoptosis in cancer cells via caspase- 9 activation and cytochrome c release. Carcinogenesis, 2003; 24(3): 427-33

7. Schaffner-Sabba K, Schmidt-Ruppin KH, Wehrli W et al: Beta-Lapachone: Synthesis of derivatives and activities in tumor models. J Med Chem, 1984; 27(8): 990-94 study reported that beta-lapachone exerted anti-cancer effects on prostate cancer cells via induction of programmed cell death [22]. The mTOR/PI3K/AKT signalling pathway has been revealed to be triggered in tumor cells and is thought to be a central therapeutic target for treatment of various cancers [23]. Therefore, we investigated the effects of beta-lapachone on this signalling cascade. We found that beta-lapachone concentration-dependently blocks this signalling pathway. The ability of cancer cells to migrate to distant organs is a vital step in the metastasis of all cancers [24]. Herein, we found that beta-lapachone suppressed the migration and invasion abilities of nasopharyngeal tumor cells. We also assessed the effects of beta-lapachone on ROS and MMP levels, finding that beta-lapachone increased ROS levels in HNE1 cells and decreased MMP levels. Beta-lapachone also triggered the production of autophagosomes in the HNE1 nasopharyngeal carcinoma cells, which was associated with an upsurge in LC3 II expression and decreased p62 expression. These findings are in agreement with previous studies showing that beta-lapachone triggers reactive oxygen species [ROS]-mediated autophagic death of glioma U87 cell [25].

\section{Conclusions}

We found that beta-lapachone can inhibit the growth of nasopharyngeal cancer cells via blockade of the mTOR/PI3KAKT signalling pathway. Beta-lapachone treatment of HNE1 cells also induced autophagy and suppressed cell migration and invasion. Hence, beta-lapachone appears to be a useful agent for treatment of nasopharyngeal carcinoma and warrants further investigation.

\section{Conflict of interest}

None.

8. Ough M, Lewis A, Bey EA et al: Efficacy of beta-lapachone in pancreatic cancer treatment: exploiting the novel, therapeutic target NQO1. Cancer Biol Ther, 2005; 4(1): 102-9

9. Huang L, Pardee AB: beta-lapachone induces cell cycle arrest and apoptosis in human colon cancer cells. Mol Med, 1999; 5(11): 711-20

10. Seow HF: Synergistic combinations of small molecule kinase inhibitors: Implications for reducing toxicities in nasopharyngeal carcinoma treatment. Journal of NasoPharyngeal Carcinoma, 2017; 4(4)

11. Chen J, Qi J, Yu BL et al: A retrospective study to compare five induction chemotherapy regimens prior to radiotherapy in the reduction of regional lymph node size in patients with nasopharyngeal carcinoma. Med Sci Monit, 2018; 24: 2562-68

12. Wang X, Zhang JJ, Sun YM et al: Triptolide induces apoptosis and synergiz es with cisplatin in cisplatin-resistant HNE1/DDP nasopharyngeal cancer cells. Folia Biol (Praha), 2015; 61(5): 195-202

13. Zhang $\mathrm{P}$, Liu $\mathrm{H}$, Xia F et al: Epithelial-mesenchymal transition is necessary for acquired resistance to cisplatin and increases the metastatic potential of nasopharyngeal carcinoma cells. Int J Mol Med, 2014; 33(1): 151-59 
14. Xiao X, Zhang Z, Chang ET et al: Medical history, medication use, and risk of nasopharyngeal carcinoma. Am J Epidemiol, 2018; 26: 2117-25

15. Adham M, Kurniawan AN, Muhtadi Al et al: Nasopharyngeal carcinoma in Indonesia: Epidemiology, incidence, signs, and symptoms at presentation. Chin J Cancer, 2012; 31(4): 185-96

16. Chang ET, Adami HO: The enigmatic epidemiology of nasopharyngeal carcinoma. Cancer Epidemiol Biomarkers Prev, 2006; 15(10): 1765-77

17. Haleshappa RA, Thanky AH, Kuntegowdanahalli $L$ et al: Epidemiology and outcomes of nasopharyngeal carcinoma: Experience from a regional cancer center in Southern India. South Asian J Cancer, 2017; 6: 122-24

18. Pardee AB, Li YZ, Li CJ: Cancer therapy with beta-lapachone. Curr Cancer Drug Targets, 2002; 2(3): 227-42

19. Lamberti MJ, Vittar NB, da Silva Fde C et al: Synergistic enhancement of antitumor effect of $\beta$-Lapachone by photodynamic induction of quinone oxidoreductase (NQ01). Phytomedicine, 2013; 20(11): 1007-12
20. Li JZ, Ke Y, Misra HP et al: Mechanistic studies of cancer cell mitochondriaand NQO1-mediated redox activation of beta-lapachone, a potentially novel anticancer agent. Toxicol Appl Pharmacol, 2014; 281(3): 285-93

21. Bey EA, Bentle MS, Reinicke KE et al: An NQO1-and PARP-1-mediated cell death pathway induced in non-small-cell lung cancer cells by $\beta$-lapachone. Proc Natl Acad Sci USA, 2007; 104(28): 11832-37

22. Planchon SM, Pink JJ, Tagliarino $C$ et al: $\beta$-Lapachone-induced apoptosis in human prostate cancer cells: Involvement of NQ01/xip3. Exp Cell Res, 2001; 267(1): 95-106

23. Liu J, Liu X, Ma W et al: Anticancer activity of cucurbitacin-A in ovarian cancer cell line SKOV3 involves cell cycle arrest, apoptosis and inhibition of mTOR/PI3K/Akt signaling pathway. J BUON, 2018; 23(1): 124-28

24. Yamaguchi $\mathrm{H}$, Condeelis J: Regulation of the actin cytoskeleton in cancer cell migration and invasion. Biochim Biophys Acta, 2007; 1773(5): 642-52

25. Park EJ, Choi KS, Kwon TK: $\beta$-Lapachone-induced reactive oxygen species (ROS) generation mediates autophagic cell death in glioma U87 MG cells. Chem Biol Interact, 2011; 189(1-2): 37-44 